\title{
Rolamentos e subjetivações: Ó isso aí
}

Rollings and subjectivations: Ó isso aí

\section{Ana Goldenstein Carvalhaes}

Ana Goldenstein Carvalhaes

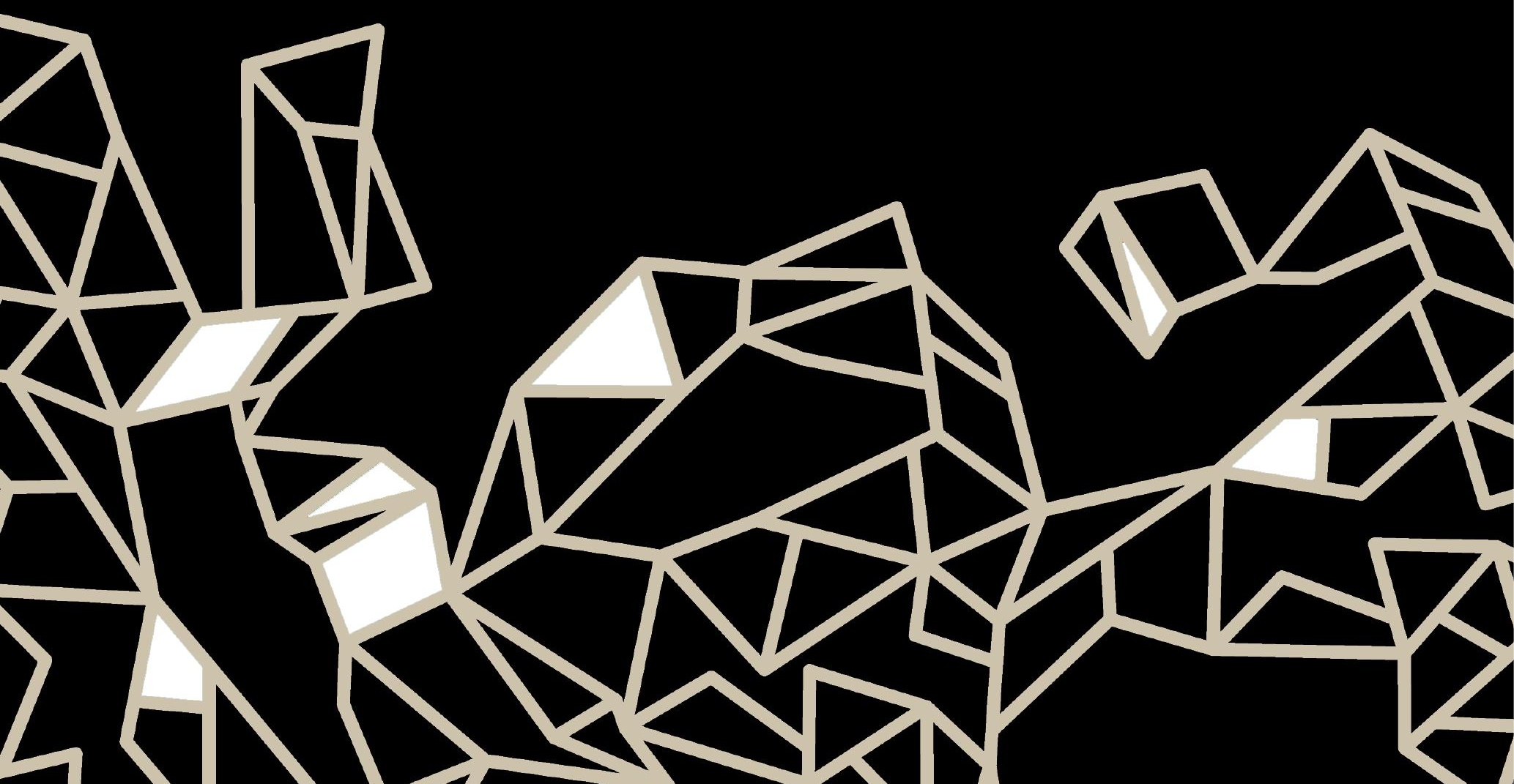




\section{Resumo}

Através de certo desprendimento da representação e certo abandono das individualidades dos performers, Ó é uma peça que opera a dessubjetivação, acessando sensações invisíveis do corpo. Por meio da repetição, apresenta-nos a duração em sua concretude. Ela não tem os signos como foco do trabalho. Livre da coerção da língua, volta-se para as forças que reverberam no público. Ainda não podemos significar o que acontece ali e já sentimos tanta coisa. Voltada para seus efeitos de ressonância, testemunhamos a própria transformação no fluxo de seu desenrolar. Pequenas diferenças operam nossa percepção da peça e de nós mesmos. O trabalho reverbera na esfera subjetiva: ao voltar, reconhecemo-nos diferentes. O retorno do sujeito não é o mesmo, mas deslocado e aumentado artisticamente.

Palavras-chaves: Modos de subjetivação, Duração, Diferença, Desenrolar, Ó.

\section{Abstract}

Through certain detachment of representation and certain abandonment of individuality of the performers, Ó is a performance that operates desubjectivation accessing invisible body sensations. Through repetition, it presents the duration in its concreteness. The signs are not the focus of that work. Free from coercion of the language, it turns to the forces that reverberate in the public. Before giving meaning to what we see, we already feel so much. Driven to the effects of resonance, we witness the change itself in the flow of its unrolling. Small differences operate our perception of the play and of ourselves. The work reverberates in the subjective sphere: when we come back, we recognize ourselves different. The return of the subject is not the same but shifted and artistically increased. Keywords: Modes of subjectivation, Duration, Difference, Unrolling, Ó.

A performance tem uma relação histórica e genética com o formalismo. Está em sua disposição à autorreflexão, na sua inclinação em colocar as formas em jogo. Ao mesmo tempo, ela opera a ruptura das estruturas formais, faz copular estruturas contrárias e às vezes não compatíveis, deslocando sistemas e semióticas já conhecidas. Anima intensidades sem nome, faz emergir o demasiado. 
Paralelamente à estrutura formal de uma obra, há um plano do acontecimento. Muitos trabalhos performáticos operam no plano da imanência. Falo de uma arte a princípio não focada e dirigida à sintaxe, mas à sua ressonância na vida, através do plano das forças.

Ó foi o primeiro trabalho que vi de Cristian Duarte, em cocriação com Aline Bonamin, Bruno Levorin, Felipe Stocco, Tom Monteiro e equipe. Esse texto é inteiramente apoiado na experiência que tive ao assistir a performance no último dia da temporada na Casa do Povo, em São Paulo, em abril de 2016. Ó pode ser entendida como uma obra sobre duração.

É uma peça absolutamente formal, em sua limpeza e nudez, na economia de recursos, no seu uso do espaço, seguindo "investigação pelo minimalismo". A tendência é pensarmos no material de que ela é feita e todos os elementos da cena: corpos são apenas corpos, em sua materialidade - eles não representam nada além do que são e do que fazem naquele momento.

Como no minimalismo, os performers se utilizam da repetição. São dois corpos rolando no espaço liso da sala vazia (no chão, apenas as caixas que amplificam um ambiente sonoro), sem parar, durante todo o tempo. Os corpos vão rolando para um lado, e quando encontram um bloqueio que lhes faça resistência eles mudam o sentido do rolamento. Com alguns bloqueios que entortam seus corpos, eles mudam também as direções. Logo percebemos que a cena é apenas isso: dois corpos rolando e rolando, percorrendo todo o espaço, organizando-o com seu surgir e ressurgir. Sabemos o que vai acontecer dali para frente, será sempre igual. Mas muita coisa acontece. O minimalismo também se preocupa em estimular o espectador sobre o efeito que os materiais e objetos produzem em sua volta, no espaço. Bater e voltar, aparecer e desaparecer entre o público: com o tempo, cria-se um ritmo. Parece que, ao rolar, eles vão carregando uma pilha, como se carrega uma dessas baterias manuais: como se seus corpos em relação criassem um campo de indução eletromagnética e produzissem energia elétrica potencial: vão carregando o espaço até formar o campo da cena que nos prende - estamos imantados na performance. É que os rolamentos carregam uma potência virtual daquilo que a cena pode ser.

Há uma dimensão impessoal dos performers, que de certa forma abandonam suas individualidades, retiram seus eus, tornam-se apenas figuras retiram o "artista" que expõe suas virtudes como dançarino, esperando seus 
aplausos. É uma forma de dessubjetivação. Ao se retirarem, entregam o corpo inteiro ao chão e dão espaço para outra(o)s coisas surgirem. Não há um "se" como em "rolam-se". Eles se retiram de cena para deixar o puro agir dos corpos no espaço, como se o rolar fosse um agir sem intensões, apenas rolamentos (como os objetos dispostos em série numa obra minimalista). Há certa entrega do material corporal a um movimento. Certo despropósito é fundamental nessa lógica, pois livra nosso olhar para ver simplesmente o combate entre os corpos e a sala. Abrem possibilidade para o acontecimento: o encontro com o público. $\mathrm{E}$ abrem também a forma de nos relacionarmos com a obra.

Ali não se criam metáforas, e, como já dissemos, os rolamentos não são representações de nada. Não há expectativas nem intensões por trás deles. O rolamento parece realizado como um agir, nos termos de Deligny (2015) em suas experiências com crianças autistas na França. Trata-se de um agir anterior ao pensamento sobre ele, antes da organização de um projeto para ele. Não se projeta um plano para agir; como a aranha que começa a tecer sua teia, o agir simplesmente acontece. É anterior aos progressos do mundo simbólico e à fala. A linguagem simbólica segue como um trator grosseiro que "varre tanto árvores como raras gramíneas." É que a linguagem é um tanto dissimulada: ela finge não possuir falhas e não reconhece seus erros de comunicação. Não reconhece esse agir não circunscrito à linguagem, observado também nos outros bichos.

O rolamento seria então a forma a-sígnica da performance Ó. Como um agir espontâneo, "inteiramente entregue ao inato que os anima" (DELIGNY, 2015, p. 29). Esse tipo de agir possui por si só uma força que é de todo interessante para os artistas. Como uma possibilidade de novos caminhos para a criação, livre da coerção da linguagem. Esse rolar espontâneo e sem cessar pelo chão parece estar livre para ir até o limite. É um deixar mover inato como espaço para pura criação de algo novo.

No agir de Deligny há também uma recusa ao indivíduo, no caminho para a dessubjetivação (PELBART, 2013). Singularidades aparecem, mas não estão subordinadas ou remetidas ao indivíduo-artista que se apresenta diante de nós. Essa é uma característica performática, e é nesse aspecto que entendo as figuras em cena em Ó, mais como performers do que como dançarinos. A ação acontece exteriormente ao sujeito. Mostra o que o excede. Como uma persona performática, faz operar máquinas simbólicas e sígnicas, livre 
da identidade cristalizada do eu do ator. Tal agir dessubjetivado pode ajudar aqueles performers que trabalham com autobiografia a ampliar suas criações para além da autorreferência, da arte-terapia ou da masturbação pública.

Mas, afinal, o que é uma obra orientada pelas forças, sem estar submetida a ou em função da linguagem simbólica? Para Gilles Deleuze e Félix Guattari (1995), o simbólico não é estruturante, ele já é estruturado. Poderíamos, por exemplo, falar de uma obra que não traz a priori uma imagem de si? Uma obra que sentimos, antes de ter que entendê-la? Que só consegue construir significados em um momento posterior? Trata-se de experiência apenas pessoal? Às vezes a experiência só se faz quando compartilhada. A presença viva do outro que permite aquilo que se cria em conjunto, que só acontece completamente com o público.

Em Ó, ritmos implicados nos chamam para dentro e para fora da ação. Elementos ecoam, fazem conexão e tornam-se nossos pares. A princípio cruzamos com os artistas pelo olhar. Eles olham e nos olham. Nós, o público, os olhamos. O olhar viaja o tempo todo. Com o tempo, o público também vai se abrindo, e mudando. Como diz Bergson, cada visão é um possível toque. Nossa presença acaba cedendo de alguma forma àquela situação. Entregamo-nos passivamente ao ritmo, à sensação. Em ressonância interna com os performers, ligamos nossa intuição. Algo vai mudando aos nossos olhos e, no entanto, nada mudou na cena, lá está a mesma repetição dos rolamentos - é o carregamento de um fluxo intenso.

Na coincidência entre "a atenção que se fixa e o tempo que foge," nos termos de Bergson (2006, p. 6), vivemos e sentimos a duração em seu estado puro. De acordo com o autor, a duração é essa própria mudança que testemunhamos no fluxo de rolamentos, em sua "continuidade de transições": são as pequenas diferenças... A cena dura enquanto aguentamos ver os rolamentos mudando os corpos. Entender essa obra como uma obra voltada para as forças que ela cria é também entender sua duração como a própria mudança, vê-la se diferenciando do que era antes. $E$ desde o momento em que entramos na sala os performers vão mudando de contorno; muda também a forma como se relacionam com o chão. Muda a natureza dos corpos e muda nossa relação com eles.

Isso também se faz possível com o desprendimento da representação, dos signos, de uma narração: nessa sensação da duração, percebemos os corpos 
ali onde estão, naquela concretude: "a percepção nos coloca de súbito na matéria, é impessoal e coincide com o objeto percebido" (DELEUZE, 2008, p. 17).

\section{Conexões - 0 afeto liga dinâmicas contagiantes}

Os acontecimentos sempre mudam em função da presença dos espectadores - muito se cria com o público. Aqui, o público constrói o "palco": ou abre espaços para o rolamento, ou constrói barreiras que são incorporadas na peça. No dia em que assisti, estava lotado, havia pouco espaço para rolar. Pessoas são sujeitos para se relacionar, assim como o chão. Há também o espaço para contato subjetivo que o público abre ou não. Há uma ação subjetiva do público sobre os performers, uma ação sobre os dois bailarinos (aquela força que sempre sentimos quando estamos em cena). Parece que todos os corpos, entrando em certa frequência ou ritmo com o agir-rolamento dos bailarinos, estabelecem uma copresença.

Com o tempo, os dois roladores começam a responder a esse contato (ou nós que passamos a percebê-lo - é parte da transformação que testemunhamos, do surgimento de algo diferente naquela repetição). Pois com o tempo podemos seguir seus dois rostos em movimento, e se pesca aqui e ali uma sensação pelas suas faces. As faces não sabem o que encontrarão naquele público - qual a fauna daquele dia? A cada dia, novos bichos povoam o espaço, às vezes cúmplices, às vezes distanciados daquele agir-rolamento. É ao cruzar com o olhar que entendemos mais o que está se passando, pois vemos nascer um desejo. São corpos em desejo de movimento e, depois, corpos em desejo de contato. Olhos abertos para uma conexão. Também vi um cuidado com o corpo que está aberto e suscetível a tudo.

Quanto mais passivos estamos, mais forte a inscrição da obra em nossos corpos. Na contemplação da performance, estamos todos também um tanto abandonados e desprendidos de nosso eu, conectados e agregados de forma criativa àquelas duas figuras rolando no chão. Eu estava entregue àquela vibração e à intensidade da obra. Toquei a bailarina quando rolou até mim. Sua mão estava receptível ao nosso contato, era um toque generoso e respeitoso (raro). Pela pele, pude sentir o que se passava por dentro dela. Era um gesto dissociado da experiência simbólica, ela não queria me dizer 
nada. Por alguns segundos manteve minha mão na dela, segurando-me e me olhando nos olhos - não era pretensiosa, ao contrário, era francamente sensível ao meu toque. Era quase como se estivesse em meu colo. Pedia minha abertura, desejava meu contato e desejava trocar comigo. Foi um momento forte de conexão. Ficamos lá por um tempo até que ela voltou a rolar novamente. Momentos depois vi o mesmo do outro bailarino - ele rolava sobre o público, passando por cima dos pés ou de algum pedaço de corpo. Depois acabava no colo de alguém que estava sentado no chão, e depois mais uma vez, e oferecendo seu peso aos outros corpos, conectava olho no olho.

Através dos olhos, havia um compartilhamento intenso, íntimo e estranho. Há algo de erótico nesse tipo de conexão com o público. Na relação entre os corpos e no contato com o público. Compartilhar pode ser erótico.

Ao mesmo tempo, era de uma intensidade contagiante. Só depois leio o release do trabalho: "O Laboratório Ó no MITsp deseja arremessar a percepção para torná-la uma produção que orienta a gestão da obra e suas possibilidades. Excitar a matéria, para nós, não é impulso para estabelecer segurança ao que pode vir a ser. Antes, é alimentá-la com um entendimento de duração que, mergulhado em uma prática de sentidos e sensações, dirige a trajetória para uma lógica de reverberação".

Lembrei-me de uma performance que fiz em uma fábrica na Mooca com o Gabriel Kerhart nos idos de 2000 - tinha ali alguma abertura para o desconhecido que era de todo excitante e de todo desconhecido mesmo - breu, mistério, e ao mesmo tempo luz, magia, força, para algo que vinha de nós dele, do desconhecido dele, e da conexão com ele, e do que poderia surgir se nos encontrássemos naquele lugar. Tínhamos uma partitura, mas deixamos aberto um espaço para o que realmente não sabíamos o que era. Desde então fico à procura dessa sensação em cena, da criação de um espaço-tempo espontâneo que abre para algo ainda não revelado, que será criado ali, sensação que só se iguala a certas experiências da infância. Conectar com um outro, para em conjunto ver algo desconhecido surgir e depois evanescer, exige muita delicadeza, pois é uma situação muito frágil. Isso está em Ó. É estar aberto para a conexão como potência criativa, que em cena pode ser muito poético. É dessa lógica de reverberação. 


\section{A cena final}

Por fim, a dupla simplesmente se levanta e executa uma ação que não entendemos o porquê, mas já não importa há muito tempo (estão em relação ao mito de Orfeu1). Pegam uma caixinha com um pó prateado e um fio. Esticam o fio alto e tencionam, um na frente do outro. É o fio da conexão teso. Tentam soltar o fio ao mesmo tempo, mas não conseguem; e recomeçam, por três vezes. Na terceira, ela olha para trás, para ele o fio cai no chão, a luz se apaga.

Os sentidos estéticos vão se criando, emergindo sem percebermos. Voltamos ao espaço, aos signos, ao plano organizado pelo simbólico, ao nosso corpo, às nossas vidas - isso tudo sempre esteve lá, em paralelo. Estamos comprometidos em organizar novamente nossos diversos eus espalhados pela performance. Voltamos a nós, depois dessa deriva a qual fomos jogados pela performance, mas voltamos deslocados. Vamos nos encontrando à meia luz, que não é acesa de uma vez; não vemos os atores como indivíduos no aplauso, apenas suas silhuetas (uma causalidade daquela noite ou uma escolha do grupo? - deu certo). É o tipo de trabalho que reverbera na esfera subjetiva: reconhecemo-nos diferentes. O retorno do sujeito não é o mesmo, mas deslocado e ampliado artisticamente. Está mais autônomo.

\section{Referências bibliográficas}

BERGSON, H. Introdução. In: O Pensamento e o Movente: ensaios e conferências. São Paulo: Martins Fontes, 2006.

DELEUZE, G. Bergsonismo. São Paulo: Editora 34, 1999.

DELEUZE, G.; GUATTARI, F. Mil Platôs. São Paulo: Editora 34, 1996.

DELIGNY, F. O Aracniano e outros textos. São Paulo: N-1, 2015.

PELBART, P. P. Linhas Erráticas. In: 0 avesso do niilismo: cartografias do esgotamento. São Paulo: N-1, 2013.

Recebido em 10/10/2016 Aprovado em 06/12/2016

Publicado em 21/12/2016

1 Veja "Sobre a criação" em: <http://www.cristianduarte.net/available-works/o-na-mitsp-2016/>. Acesso em: 20 nov. 2016. 